\title{
Inventory Model for Medium and Small Scale Enterprises
}

\author{
Komati Durga Prasad ${ }^{1}$, Soofi Asra Mubeen ${ }^{2}$, Banda Rajani ${ }^{3}$ \\ ${ }^{1}$ ICFAI Law School, ICFAI Foundation for Higher Education, Hyderabad, India \\ ${ }^{2}$ Department of Management, Higher College of Technology, Muscat, Oman \\ ${ }^{2}$ Department of Management, Chaitanya Deemed to Be University, Warangal, India
}

Email address:

komatiprasad@gmail.com (K. D. Prasad),soofi.asra@gmail.com (S. A. Mubeen),komatirajani@gmail.com(B. Rajani)

\section{To cite this article:}

Komati Durga Prasad, Soofi Asra Mubeen, Banda Rajani. Inventory Model for Medium and Small Scale Enterprises. Science Journal of Business and Management. Vol. 8, No. 2, 2020, pp. 102-105. doi: 10.11648/j.sjbm.20200802.08

Received: November 27, 2019; Accepted: January 4, 2020; Published: June 23, 2020

\begin{abstract}
At the enterprise level, inventory holding assumes significance importance, as inventories represent an oversized proportion of the entire assets of the many issues. Proper control over inventories provides the management with flexibility in making purchases systematically rather than buying strictly according to the production schedule and hand to mouth supplies. The major drawback of internal control is to maximize profitableness by reconciliation investment price of materials against what's needed to sustain level operations. The purpose of this paper is to study the status of inventory holding the Medium and Scale Enterprises. An attempt is also made to test the optimality of inventory holding in these enterprises concerning the cost of sales by applying simple regression models For testing the optimality of inventory holding in relationship cost of sales, correlation coefficient, coefficient of determination (R-square), F-test through ANOVA, regression coefficients and their standard errors, values of t-statistics and their Pvalues have been computed. The analysis reveals that Medium and Light Engineering Central Public Enterprises could reduce the inventory holding in terms of the number of days of consumption, cost of production and cost of sales.
\end{abstract}

Keywords: Inventories, Medium, and Small Enterprises, Regression, ANOVA

\section{Introduction}

Inventory control deals with the acquisition, storage, handling and use of inventories, therefore, it needs to maintain the availability of the material when needed. Providing adequate cushion for contingencies account for the most economy and minimum wastage [1]. At the enterprise level, inventory holding assumes significance importance, as inventories represent an oversized proportion of the entire assets of the many issues [7].

It requires a substantial investment of capital besides involving the cost of storage and handling as well as the risk of damage, loss, and obsolescence [4]. To minimize costs and also to ensure that capital is not unnecessarily locked up, inventories must be efficiently managed. Errors in inventory management cannot be rectified, as it is the least liquid among all the current assets. The major drawback of internal control is to maximize profitableness by reconciliation investment price of materials against what's needed to sustain level operations [3]. Proper control over inventories provides the management with flexibility in making purchases systematically rather than buying strictly according to the production schedule and hand to mouth supplies [3]. It also permits flexibility in production management and marketing. Through the production need not be geared to immediate sales, this does not warrant increasing the level of inventories indiscriminately.

Efficient management aims at increasing the level of inventories as long as the resulting economies and benefits exceed the total cost of holding such inventories and benefits exceed the total cost of holding such inventories [7].

Appropriate control over inventories affects the operational efficiency and profitability of the organization.

It also helps in achieving a higher return on investment by minimizing locked up working capital and also in improving the cash flow and liquidity position.

Inventory control should meet two opposing needs. Viz

1. Maintenance of an inventory of sufficient size and diversity for efficient operations and

2. Maintenance of financially favorable inventory.

Public Enterprises, of late, are subjected to the criticism that their economic performance is not satisfactory [2]. 
Among various issues affecting the performance of manufacturing concerns, inventory control is a major aspect.

\section{Objectives the Paper}

The purpose of this paper is to study the status of inventory holding the Medium and Scale Enterprises. An attempt is also made to test the optimality of inventory holding in these enterprises concerning the cost of sales by applying simple regression models. More precisely, the analysis enables to identify;

1. Whether the inventories of the undertakings moved in constant proportion to the cost of sales

2. Whether the inventory holding in the undertakings moved in square root relationship to cost of sales.

3. Whether the undertakings enjoyed economies of scale/suffered diseconomies of scale in respect of inventory holding.

\section{Data and Methodology}

Experience has given some idea of approximate limits within which inventories vis-à-vis the sales would move. This approximate limit suggests three possibilities. Firstly, inventories may move in constant ratio with their usage. Secondly, according to the established belief, with increasing consumption of sales, a relatively lesser volume of inventories are needed and under ideal conditions of effective management, inventories should move in square-foot relationship with their usage. The third alternative is that inventories increase in between these two extremes.

To assess the status of inventory holding, trends in all inventories, raw materials, work-in-progress, and finished goods in terms of cost of sales, consumption, cost of production and net sales respectively have been computed and presented in terms of several days. For testing the optimality of inventory holding in relationship cost of sales, correlation coefficient, coefficient of determination (Rsquare), F-test through ANOVA, regression coefficients and their standard errors, values of $\mathrm{t}$-statistics and their P-values have been computed.

To test the optimality of inventory holding, the following simple regression models have been applied to the timeseries data of the sample undertaking:

1. $Y=a+b x$

2. $\mathrm{Y}=\mathrm{A}+\mathrm{bvx}$

3. $\mathrm{Y}=\mathrm{ax}$

Where, $\mathrm{Y}=$ Inventories, $\mathrm{a} / \mathrm{a}=$ intercept which indicates the level of safety stock.

$\mathrm{b}=$ regression coefficient, and $\mathrm{X}=$ cost of sales.

The value of a indicates the degree of economies of scale enjoyed/suffered by the undertakings. The values of coefficient a, b, a, a have been tested at 95 percent confidence level. For the present study, relevant data for the years 2008 -09 to 2017-18 have been obtained from various issues of Public Enterprises Survey-Annual Reports on the working of Industrial and Commercial Undertakings of the Central Government published by Government of India.

\section{Inventory Behaviour - An Analysis}

Trends in Inventories in Medium and Small Scale Enterprises: To examine the trends in inventories in a sample enterprise, trends in all inventories, cost of sales, raw material, work in progress, finished goods have been computed and presented in Table 1. Trends values have been computed using the following formula:

$$
\text { Trend Value }=\{(-) /\} \times 100
$$

Where Value of inventories/ cost of sales of the previous year

Value of inventories/cost of sales of the current year

Table 1. Trends in Inventories in Medium and Light Engineering CPEPSs in India From 2008-2009 to 2017-2018 (Rs. In Crores/No. of days).

\begin{tabular}{|c|c|c|c|c|c|c|}
\hline Year & Average Inventory & Cost of Sales & $\begin{array}{l}\text { Inventory cost of } \\
\text { sales }\end{array}$ & $\begin{array}{l}\text { Raw materials cost of } \\
\text { production }\end{array}$ & $\begin{array}{l}\text { WIP: Cost of } \\
\text { Production }\end{array}$ & $\begin{array}{l}\text { Finished goods: Net } \\
\text { sales }\end{array}$ \\
\hline $2008-2009$ & 2253.66 & 4773.51 & 172 & 166 & 55 & 30 \\
\hline 2009-2010 & 2323.83 & $4908.7(3.11)$ & $173(2.83)$ & 165 & 51 & 33 \\
\hline $2010-2011$ & 2258.25 & $5069.29(-2.82)$ & $163(3.27)$ & 161 & 47 & 32 \\
\hline 2011-2012 & 2091.73 & $5444.19(-7.37)$ & $140(7.40)$ & 161 & 43 & 24 \\
\hline $2012-2013$ & 1897.29 & $5927.17(-9.30)$ & $117(8.87)$ & 141 & 39 & 20 \\
\hline 2013-2014 & 1741.54 & $6383.14(-8.21)$ & $100(7.70)$ & 129 & 27 & 19 \\
\hline 2014-2015 & 1949.84 & $6314.11(12.00)$ & $113(-1.08)$ & 130 & 28 & 62 \\
\hline $2015-2016$ & 2470.09 & $7776.70(26.68)$ & $116(23.16)$ & 122 & 30 & 58 \\
\hline 2016-2017 & 2790.7 & $7920.89(1.85)$ & 129 & 121 & 17 & 70 \\
\hline $2017-2018$ & 2939.09 & $7955.62(0.44)$ & 135 & 128 & 7 & 72 \\
\hline
\end{tabular}

Sources: Complied from Public Enterprises Survey - Annual Reports.

Figures in brackets indicate trends

From the table, it is clear that inventories increased by 3.11 per year in 2010-11 over 2009-10. From 2011-12 to 20132014, the level of inventories registered negative trends indicating improvement in inventory management. This trend could not persist in the rest of the study period. In 2015-16, inventories have increased by 26.68 percent over the year 2014-15. However, in 2016-2017 and 2017-2018, there has been a significant decline in the cost of sales.

Analysis in respect of raw materials expresses in terms of several days consumption revealed that from 2008-2009 to 
2011-2012 there has been an increase in the cost of sales ranging from 2.83 percent to 8.87 percent. In 2013-14 there has been some improvement and this improved further in 2014-15. However, in 2015-16, it has been as high as 23.16 percent. But in 2016-17 and 2017-18, there has been a significant decline in the cost of sale.

Analysis in respect of raw materials expressed in terms of several day's consumptions revealed that from 20018-09 to 2013-14, there has been a decline in the inventory level. However, this improvement could not be found in the rest of the years.

Analysis of work in progress and finished goods inventory revealed that on the whole, the management succeeded in reducing the level of work in progress in terms of the number of days of cost of production. However, the trend in finished goods inventory showed an increasing tendency as it has increased from 30 days in 20018-09 to 72 days in 2017-18.

Test of Optimality

To test the optimality of inventory holding concerning the cost of sales, simple regression models have been applied and the results have been presented in Tables 2-4.

Application of Regression Model $-\mathrm{I}$ : $\mathrm{Y}=\mathrm{a}=\mathrm{bX}$

A simple regression model of $y=a+b x$ has been applied to test the optimality of inventory holding. And the results are presented in Table 2.

Table 2. Regression Statstics Summary Results of Model I: $y=a+b x$.

\begin{tabular}{llllll}
\hline Multiple R & & 0.568765 & \\
R Square & & & 0.323494 & \\
Standard Error & & & 33341.68 & \\
Observations & & & 10 & \\
\hline \multicolumn{7}{c}{} \\
\hline ANOVA & DF & SS & MS & F & Signif. F \\
\hline \multicolumn{7}{c}{ Regression } & 1 & $4.25 \mathrm{E}+09$ & $4.25 \mathrm{E}+09$ & 3.82547 & 0.086205 \\
Residual & 8 & $8.89 \mathrm{E}+09$ & $1.11 \mathrm{E}+09$ & & \\
Total & 9 & $1.31 \mathrm{E}+10$ & & & \\
\hline
\end{tabular}

\begin{tabular}{lllll}
\hline t- Test & & & & \\
\hline & Coefficient & Std. Error & t-Statistic & p- value \\
\hline Intercept & 118971.6 & 56310.4 & $2.11 \mathrm{E}+00$ & 0.06758 \\
$X$ & 0.173176 & 0.088541 & 1.955881 & 0.086205 \\
\hline
\end{tabular}

The value of R-Square is 0.323494 . This value indicates that about 32 percent of the change in the level of inventories is due to the change in the sales level. Therefore about 67 percent of the change in inventory level is not in response to the change in sales but due to other considerations.

F-ratio (3. 82547) is not significant at 5 percent level of significance as its p-value $(0.086205)$ is greater than 0.05 . Thus, the relationship between inventories and sales is considered as an occurrence chance. Therefore, the variance due to regression with the unexplained variance is not significant.

The coefficient in respect of inventory intercept represents the level of safety stock. The results reveal that the policy matter concerning the maintenance of safety stock is not in proportion to the level of sales.

Further, the value of the coefficient in respect of sales is positive, which shows that the level of inventories is positively related to sales. However, $t$-values for intercept and sales coefficient indicated poor regression relationship. Thus the Excel summary Output in respect of Regression Statistics reveals that the inventories are not moving in a linear relationship to the sales.

APPLICATION OF MODEL $-\mathrm{II}$; $\mathrm{Y}=\mathrm{a}+\mathrm{bvX}$

Table 3. Regresion Statistics Summary Results OF Model I: $y=a+b v X$

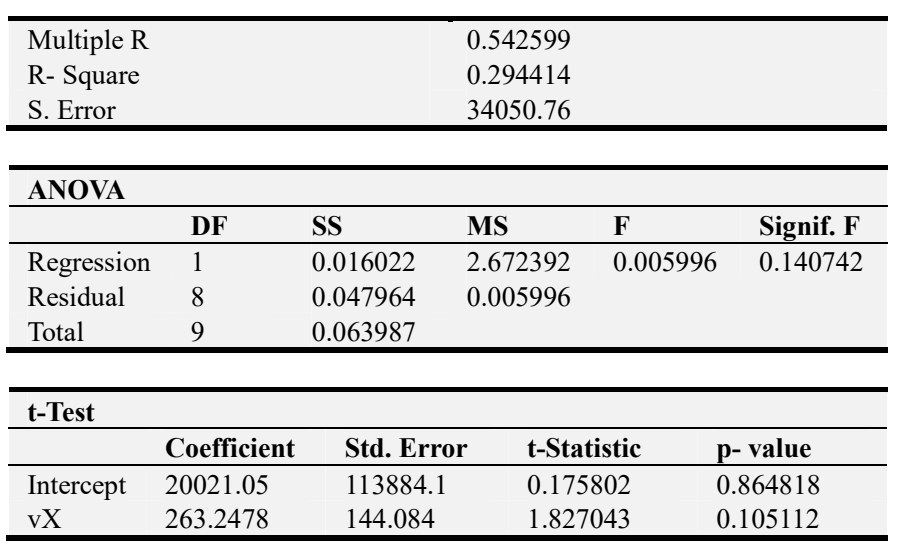

The results concerning the application of this model are presented in Table 3. The value of R-square is 0.294414 . it reveals that about 29 percent of the variation in inventory is explained by the variation in sales. Thus a greater majority i.e. 71 percent of the variation in inventories is not explained by the variation in sales.

F-ratio (3.338088) is not significant at 5 percent level of significance as its p-value $(0.105112)$ is greater than 0.05 . Thus the relationship between inventories and sales is an occurrence by chance. Therefore, the variance due to regression with the unexplained variance (residual) is not significant.

The t-values concerning intercept and sales expressed in square root relationships are significant with their corresponding critical values. As such the variable inventories and sales are behaving independently.

The discussion based on the Excel Summary Output in respect of regression statistics reveals that the inventories are not moving in square root relationship to sales.

APPLICATION OF MODEL -III OR Log $\mathrm{Y}=$ LOGa + aLOGX

Table 4. Excel Summary Output of Model-III; $y=a X^{a}$.

\begin{tabular}{|c|c|c|c|c|c|}
\hline \multicolumn{6}{|c|}{ Regression Statistics } \\
\hline \multicolumn{3}{|l|}{ Multiple R } & \multicolumn{3}{|c|}{0.500402} \\
\hline \multicolumn{3}{|l|}{ R Square } & \multicolumn{3}{|c|}{0.250402} \\
\hline \multicolumn{3}{|l|}{ S. Er } & \multicolumn{3}{|c|}{0.077431} \\
\hline \multicolumn{3}{|l|}{ Observations } & \multicolumn{3}{|l|}{10} \\
\hline \multicolumn{6}{|l|}{ ANOVA } \\
\hline & DF & SS & MS & $\mathbf{F}$ & Signif. F \\
\hline Regression & 1 & $3.87 \mathrm{E}+09$ & $3.87 \mathrm{E}+09$ & 3.338088 & 0.105112 \\
\hline Residual & 8 & $9.28 \mathrm{E}+09$ & $1.16 \mathrm{E}+09$ & & \\
\hline Total & 9 & $1.31 \mathrm{E}+10$ & & & \\
\hline
\end{tabular}




\begin{tabular}{llllll}
\hline t- test & & & & & \\
\hline \multicolumn{1}{c}{ Coefficient } & Std. Error & t- Statistic & t-Statistic P-Value \\
\hline Intercept 2.529625 & 1.729706 & $1.46 \mathrm{E}+00$ & 0.18176 & 0.086205 \\
Log X & (a) & $4.88 \mathrm{E}-01$ & $9.88 \mathrm{E}-02$ & 1.634745 & \\
\hline
\end{tabular}

The results concerning the application of this model are presented in Table 4.

Analysis of Excel Summary Output reveals that the value of $\mathrm{R}$ square $(0.250402)$ fails to provide any meaningful evidence to believe the regression relationship between inventories and sales. Only 25 percent of the variation is explained by the regression relationship. Thus about 75 percent of the variation remains unexplained.

F-ratio, which explains the extent of the regression relationship with unexplained variance (residual) is not significant as its p-value $(0.140742)$ is greater than 0.05 . the coefficient in respect of intercept (a) and also $\log \mathrm{X}$ (a) are positive and not significant. They indicate that the companies under consideration are suffering from diseconomies. Thus the t0 values are also not significant. Therefore it may be concluded that there is no evidence to believe that the medium and light engineering industry enjoyed economies in respect of inventories.

\section{Conclusion}

The analysis reveals that Medium and Light Engineering Central Public Enterprises could reduce the inventory holding in terms of the number of days of consumption, cost of production and cost of sales.

The inventory holding of Medium and Light Engineering Enterprises did not move in constant proportion to sales. The inventory holding of the sample enterprises did not move in square root relationship to sales and the enterprises did not enjoy economies of scale in respect of inventory holding with sales.

Further, a detailed investigation of these trends revealed

1. Abnormal lead times.

2. Unscientific purchases/issuing decision

3. Heavy carrying costs,

4. Ineffective use of sales forecasting techniques,

5. Inadequate vendor rating, and

6. Lack of a strategic approach for inventory planning.

To improve the effectiveness of inventory management, it is high time for the public sector undertakings to reengineer the inventory management policies and practices with the help of Supply Chain Management/Just -In -time.

\section{References}

[1] Abor, J. and Quartey, P. (2010). 'Issues in SME Development in Ghana and South Africa', International Research Journal of Finance and Economics, Issue 39.

[2] Abanis, Turyahebwa, Sunday Arthur, Burani, Aluonzi and Eliabu Byamukama (2013), "Financial Management Practices In Small and Medium Enterprises in Selected Districts In Western Uganda”, Research Journal of finance and
Accounting, Vol. 4 (2), pp. 29-42.

[3] Adam, E. E. and Ebert, J. R. (1993): Production and Operations Management: Concepts, Models and Behaviour, 5 th edition. Prentice Hall, New Delhi. p 568

[4] Barker, T. (1989): The Essential of Material Management. McGraw Hill Book Co. London. p 261.

[5] Brown, M. J. (2017), "How important are small businesses to local economies?", Retrieved from: smallbusiness.chron.com/important-small-businesses-localeconomies-5251.html

[6] Edwardson, W. (1989): Improvement of the Small Scale Food Industry Developing Countries. UNIDO Industry Development, No. 27 p13.

[7] Harishini., L (2010). An Empirical Investigation of Inventory Management Particles of Processed Food Supply Chain in Srilanka, Manufacture perspective: A case study proceeding of the 2010. International Conference on Industrial Engineering and Operation Management Dhaka. Bangladesh.

[8] Kotut, P. K. (2003). 'Working capital management practices by Kenyan firms: A case study of firms listed in the NSE', Unpublished MBA project. Egerton University.

[9] Montgomery, D. C., Peck, E. A., \& Vining, G. G. (2015). Introduction to linear regression analysis. John Wiley \& Sons.

[10] Monisola, Olowolaju (2013), “An assessment of Inventory Management in Small and Medium Scale Industrial Enterprises in Nigeria”, European Journal of Business and Management, Vol. 5 (28), pp. 150-158.

[11] Nyamao, N. R., Patrick, O., Martin, L., Odondo, A. J., \& Simeyo, O. (2011). 'Effect of working capital management practices on financial performance: A study of small scale enterprises in Kisii South District, Kenya", African Journal of Business Management Vol. 6 (18), pp. 5807-5817, 9 May, 2012

[12] Rajeev, N., Do Inventory Management Practices Affect Economic Performance? An Empirical Evaluation of the Machine Tool SMEs in Bangalore, International Journal of Innovation and Technology Management, Vol. 4, no. 7, pp 405-422, 2010.

[13] S. Angel Raphella, S. Gomathi Nathan and G. Chitra, "Inventory Management- A Case Study", International Journal of Emerging Research in Management \&Technology, ISSN: 2278-9359, Vol. 3 (3) June 2014, pp. 94-102.

[14] Storey, D. J. (1994). Understanding the Small Business Sector. Routledge, London.

[15] Wallin, C., M., Rungtusanatham, M. J., and Rabinovich, E. (2006),"What is the "right" inventory management approach for a purchased item?", International Journal of Operations \& Production Management, Vol. 26 Iss 1 pp. 50-68.

[16] Wang, L., (2009). Study on the system optimization of inventory management of SME, IJCAI International Joint Conference on Artificial Intelligence, July 13-17, California, USA, pp. 413-416, 2009.

[17] Zipkin, P. H. (2000). Foundations of inventory management (Vol. 20). McGraw-Hill New York. 